\title{
Indications for Computed Tomography in Patients With Mild Head Injury
}

\author{
Kenichiro OnO, Kojiro WADA, Takashi TAKAHARA, and Toshiki SHIROTANi
}

\author{
Department of Neurosurgery, Japan Self Defense Forces Central Hospital, Tokyo
}

\begin{abstract}
The factors affecting outcome were analyzed in 1,064 patients, 621 males and 443 females aged 10 to 104 years (mean $46 \pm 23$ years), with mild head injury (Glasgow Coma Scale [GCS] score $\geq 14$ ) but no neurological signs presenting within 6 hours after injury. Intracranial lesion was found in $4.7 \%$ $(50 / 1,064)$, and $0.66 \%(7 / 1,064)$ required surgical treatment. The Japan Coma Scale (JCS) and GCS assessments were well correlated $(r=0.797)$. Multivariate analysis revealed significant correlations between computed tomography (CT) abnormality and age $\geq 60$ years, male sex, JCS score $\geq 1$, alcohol consumption, headache, nausea/vomiting, and transient loss of consciousness (LOC)/amnesia. Univariate analysis revealed that pedestrian in a motor vehicle accident, falling from height, and mechanisms of injuries except blows were correlated to intracranial injury. No significant correlations were found between craniofacial soft tissue injury and intracranial injury. Patients with occipital impact, nonfrontal impact, or skull fracture were more likely have intracranial lesions. Bleeding tendency was not correlated with CT abnormality. The following indications were proposed for CT: JCS score $>0$, presence of accessory symptoms (headache, nausea/vomiting, LOC/amnesia), and age $\geq 60$ years. These criteria would reduce the frequency of CT by $29 \%(309 / 1,064)$. Applying these indications to subsequent patients with GCS scores 14-15, 114 of 168 patients required CT, and intracranial lesions were found in 13. Two refused CT. Fifty-four of the 168 patients did not need CT according to the indications, but 38 of the 54 patients actually underwent CT because of social reasons $(n=21)$ or patient request $(n=17)$. These indications for CT including JCS may be useful in the management of patients with mild head injury.
\end{abstract}

Key words: mild head injury, intracranial lesion, indications for computed tomography, Japan Coma Scale, Glasgow Coma Scale, risk factor

\section{Introduction}

The Glasgow Coma Scale (GCS) is well correlated with outcome and has good interobserver reliability, ${ }^{18,21)}$ so is widely used for the neurological assessment of head injury. However, more than $90 \%$ of patients with head injury that present to the emergency department have a GCS score of $15 .{ }^{23)}$ Guidelines for such mild head injury are common in other countries, and all such classifications are based on the GCS, because GCS on admission is strongly related to intracranial injury. These guidelines are in wide agreement regarding two points: patients with clear consciousness without symptoms or risk factors can be discharged with an information sheet $t^{5,10,12,17,23,24,32,34)}$; and patients with
GCS score of less than 15 should undergo computed tomography (CT) regardless of the presence of symptoms or risk factors. ${ }^{5,10,13,23,24,29,32,34)}$ However, clinicians are divided regarding which clinical features and risk factors warrant CT in patients with GCS score of 15.

The Japan Coma Scale (JCS) is widely used by Japanese clinical facilities including the emergency services for the assessment of consciousness level. The JCS is based on arousal degree. Two studies of the JCS in patients with aneurysmal subarachnoid hemorrhage reported that the preoperative level of consciousness as measured by JCS is well correlated with the outcome. ${ }^{6,30}$ However, the validity of this scale for head injury has not been clarified. CT is widely available and less expensive in Japan (1/2 to

Received October 24, 2006; Accepted April 10, 2007

Author's present address: K. Ono, M.D., Division Surgeon, Ground Self Defense Force 7th Division Headquarters, Camp Higashichitose, Chitose, Hokkaido, Japan. 
$1 / 10$ of the cost overseas), ${ }^{15)}$ and is substantially subsidized by the health insurance system. The decision to perform imaging of a patient with clear consciousness may be influenced by social conditions such as medicolegal factors or patient demand. However, unnecessary radiation exposure and cost should be avoided if possible.

The present study analyzed the risk factors for intracranial lesion in mild head injury, to determine the indications for CT, and to evaluate the application of these indications within the Japanese health care system.

\section{Patients and Methods}

A total of 1,370 patients with head injury, aged 10 years or older and presenting within 6 hours of trauma, were assessed at a secondary medical care facility, an emergency hospital in Tokyo, during the 2-year period between May 2001 and May 2003. Two hundred twenty-five patients were excluded because their injuries were considered extremely trivial (scalp or facial wounds only), or because they refused examination or did not cooperate. Skull radiography was performed in 93 of the 225 patients, whereas 132 received consultation only, and all 225 patients were discharged after receiving head injury warning instructions. The remaining 1,145 patients underwent CT. The present study included 1,064 of these patients with GCS score $\geq 14$, consisting of 621 males and 443 females aged 10 to 104 years (mean $46 \pm 23$ years) (Fig. 1).
A duty physician ascertained the level of consciousness using the GCS and JCS (Table 1) and established or sought information regarding the following factors: Method of arrival at hospital (by ambulance, independently), age, sex, level of consciousness (GCS, JCS), consumption of alcohol immediately prior to injury, associated symptoms (headache, nausea or vomiting, transient loss of consciousness [LOC] or amnesia), craniofacial soft tissue injury (subcutaneous hematoma, abrasion, laceration, contusion), mechanism of injury (fall,

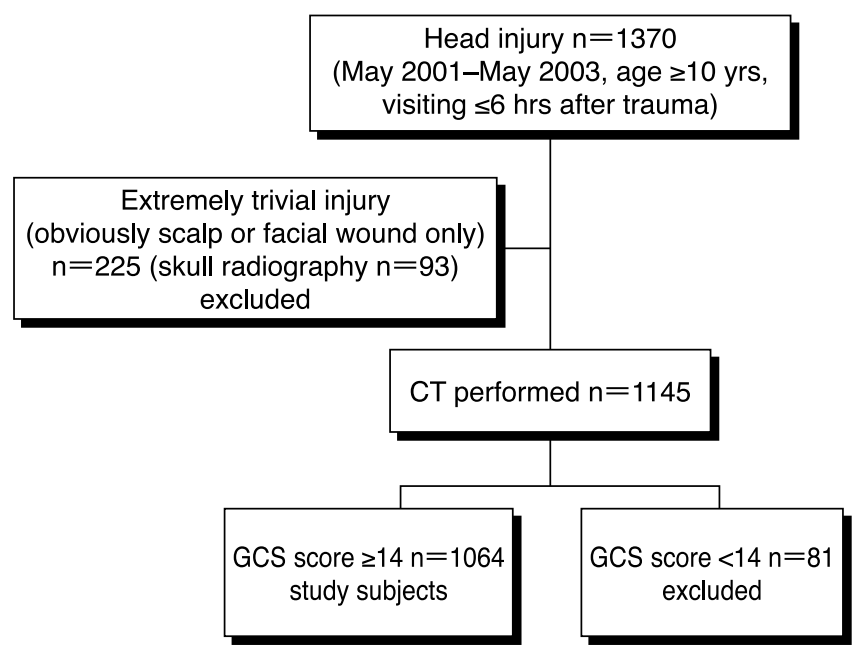

Table 1 Japan Coma Scale for grading impaired consciousness ${ }^{22}$

One-digit code:

The patient is awake without any stimuli, and is

1. almost completely conscious,

2. unable to recognize time, place, and person,

3. unable to recall name and date of birth.

Two-digit code:

The patient can be aroused

10. easily by being spoken to,

${ }^{*}$ (responsive with purposeful movements, phrases, or word)

20. with loud voice or shaking the shoulders,

*(almost steadily responsive with very simple words-yes or no, or movements)

30. only by repeated mechanical stimuli.

Then, the patient falls into the previous state by cessation of stimulation.

Three-digit code:

The patient cannot be aroused by any forceful mechanical noci stimuli, and

100. responds with movements to avoid the stimulus,

200. responds with slight movements including decerebrate and decorticate postures,

300. does not respond at all except for change in respiratory rhythm.

Revised from the Sogo Rinsho (1985; 34: 481, (C)1985, Nagai Shoten). ${ }^{*}$ Used in patients who cannot open their eyes for any reason. 
blow, fall from height, motor vehicle accident [pedestrian, bicycle, motorcycle, car]), location of impact (face, frontal, temporal, parietal, occipital; available for 895 patients), coagulopathy or bleeding tendency (antiplatelet agent or anticoagulant use, or other reason such as liver dysfunction) in 693 patients, and skull fracture (624 patients, 366 of whom underwent skull radiography or CT). Patients with normal CT were discharged home with head injury warning instructions. Some patients with remaining symptoms or alcohol intoxication were observed in the emergency department.

We analyzed the factors related to intracranial lesion by logistic regression analysis. We then proposed indications for CT in mild head injury, and applied these to 168 patients with GCS scores 14-15 who subsequently presented to our facility.

\section{Results}

The JCS and GCS assessments were well correlated ( $\mathrm{r}=0.797$ ) (Table 2). CT abnormalities were found in 50 of the 1,064 patients $(4.70 \%)$. The lesions were subdural hematoma $(\mathrm{SDH}), \mathrm{n}=10$; subarachnoid hemorrhage, $\mathrm{n}=16$; epidural hematoma (EDH), $\mathrm{n}=13$; contusion, $\mathrm{n}=10$; and pneumocephalus, $\mathrm{n}=1$. Lesion enlargement over several hours, requiring surgical treatment, was observed in seven of the 1,064 patients (0.66\%); five with $\mathrm{EDH}$, one with $\mathrm{SDH}$, and one with contusion.

Multivariate analysis revealed significant correlations between CT abnormality and age $\geq 60$ years, male sex, JCS score $\geq 1$, alcohol consumption, headache, nausea/vomiting, and LOC/amnesia (Table 3). Univariate analysis revealed that pedestrian in a motor vehicle accident, falling from height, and mechanisms of injuries except blows were correlated to intracranial injury. No significant correlations were found between craniofacial soft tissue injury and intracranial injury. Patients with occipital impact, nonfrontal impact, or skull fracture were more likely have intracranial lesions. Bleeding tendency was not correlated with CT abnormality.

On the basis of these findings, we proposed the following indications for CT: JCS score $>0$, presence of accessory symptoms (headache, nausea/ vomiting, LOC/amnesia), and age $\geq 60$ years (Fig. 2). For these indications, sensitivity was $100 \%$, specificity was $30.4 \%$, positive predictive value was $6.6 \%$, and negative predictive value was $100 \%$ (Table 4 ). Applying these indications to the 168 subsequent patients with GCS scores 14-15, 114 of 168 required $\mathrm{CT}$, and intracranial lesions were found in 13. Two refused CT. Fifty-four of the 168 patients did not
Table 2 Rank correlation of Japan Coma Scale (JCS) and Glasgow Coma Scale (GCS)

\begin{tabular}{rccc}
\hline \multirow{2}{*}{$\begin{array}{c}\text { JCS } \\
\text { score }\end{array}$} & \multicolumn{2}{c}{ GCS score } & Total \\
\cline { 2 - 3 } & 15 & 14 & \\
\hline 0 & $736(1.6 \%, 0 \%)$ & 0 & $736(1.6 \%, 0 \%)$ \\
1 & $161(11.8 \%, 1.2 \%)$ & $119(9.2 \%, 1.7 \%)$ & $280(10.7 \%, 1.4 \%)$ \\
2 & $14(7.1 \%, 7.1 \%)$ & $23(21.7 \%, 8.7 \%)$ & $37(16.2 \%, 8.1 \%)$ \\
3 & $1(0 \%, 0 \%)$ & $3(33.3 \%, 0 \%)$ & $4(25 \%, 0 \%)$ \\
10 & 0 & $7(14.3 \%, 0 \%)$ & $7(14.3 \%, 0 \%)$ \\
\hline
\end{tabular}

Total $912(3.5 \%, 0.3 \%) \quad 152(11.8 \%, 2.6 \%) 1064(4.7 \%, 0.7 \%)$

JCS and GCS show good correlation, $r=0.797$. Numbers represent total numbers of patients (percentage of CT abnormality, percentage with surgical intervention).

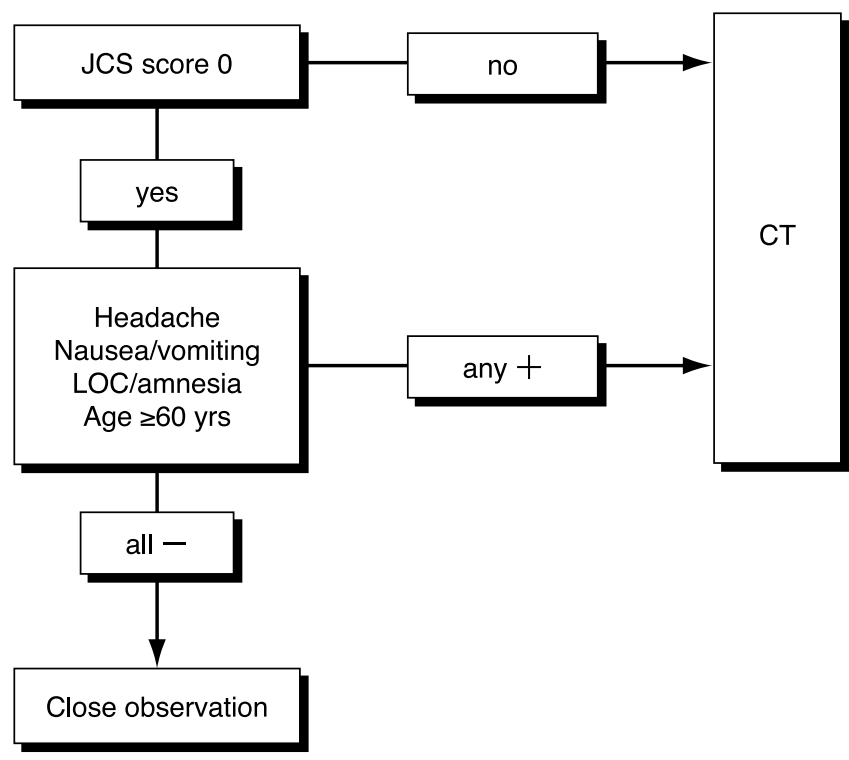

Fig. 2 Proposed indications for computed tomography (CT) in mild head injury. CT is necessary for patients with Japan Coma Scale (JCS) score $>0$. CT is also required for patients with JCS score 0 and headache, nausea/vomiting, or loss of consciousness (LOC)/amnesia, or aged $\geq 60$ years. These criteria can reduce the frequency of CT by $29 \%(309 / 1,064$ cases $)$.

need CT according to the indications, but 38 of the 54 patients actually underwent CT because of social reasons $(n=21)$ or patient request $(n=17)$. These patients had no CT abnormality. Ten of the 16 patients who did not undergo CT and consulted us again after the initial assessment had no clinical problem. 
Table 3 Association between clinical variables and computed tomography (CT) findings

\begin{tabular}{|c|c|c|c|c|c|c|c|c|}
\hline & $\begin{array}{c}\text { CT } \\
\text { abnormality } \\
\text { n=50 (\%) }\end{array}$ & $\begin{array}{c}\text { No CT } \\
\text { abnormality } \\
\mathrm{n}=1014(\%)\end{array}$ & \multicolumn{3}{|c|}{ Univariate analysis } & \multicolumn{3}{|c|}{ Multivariate analysis } \\
\hline Mean age (yrs) & $52.7 \pm 24.1$ & $46.1 \pm 23.6$ & & & 0.062 & & & \\
\hline Age $\geq 60$ yrs & $24(48)$ & $329(32.4)$ & 1.92 & $1.08-3.39$ & $<0.05$ & 3.63 & $1.77-7.44$ & $<0.001$ \\
\hline Male & $38(76)$ & $583(57.49)$ & 2.34 & $1.20-4.53$ & $<0.01$ & 2.65 & $1.26-5.60$ & $<0.05$ \\
\hline Alcohol consumption & $18(36)$ & $277(27.3)$ & 1.49 & $0.82-2.71$ & 0.18 & 0.39 & $0.19-0.82$ & $<0.05$ \\
\hline \multicolumn{9}{|l|}{ Associated symptom } \\
\hline headache & $19(38)$ & $144(14.2)$ & 3.70 & $2.03-6.73$ & $<0.001$ & 9.30 & $4.22-20.47$ & $<\mathbf{0 . 0 0 1}$ \\
\hline nausea/vomiting & $14(28)$ & $66(6.5)$ & 5.58 & $2.87-10.87$ & $<0.001$ & 4.67 & $2.02-10.78$ & $<0.001$ \\
\hline LOC/amnesia & $35(70)$ & $274(27.02)$ & 6.30 & $3.38-11.72$ & $<\mathbf{0 . 0 0 1}$ & 4.89 & $2.31-10.37$ & $<0.001$ \\
\hline Craniofacial soft tissue injury & $37(74)$ & $724(71.4)$ & 1.14 & $0.59-2.17$ & 0.69 & 1.04 & $0.48-2.27$ & 0.903 \\
\hline MVA (bicycle) & $9(18)$ & $149(14.69)$ & 1.27 & $0.60-2.67$ & 0.521 & & & \\
\hline MVA (motorcycle) & $3(6)$ & $108(10.65)$ & 0.53 & $0.16-1.74$ & 0.293 & & & \\
\hline MVA (car) & $2(4)$ & $54(5.3)$ & 0.74 & $0.17-3.12$ & 0.681 & & & \\
\hline injuries except blows & $49(98)$ & $842(83)$ & 10.00 & $1.37-72.97$ & $<0.01$ & & & \\
\hline \multicolumn{9}{|l|}{ Location of impact* } \\
\hline face & $7(14)$ & $206(24.3)$ & 0.50 & $0.22-1.13$ & 0.094 & & & \\
\hline except frontal & $47(94)$ & $661(78.2)$ & 4.36 & $1.34-14.17$ & $<\mathbf{0 . 0 1}$ & & & \\
\hline temporal & $7(14)$ & $79(9.3)$ & 1.57 & $0.68-3.62$ & 0.278 & & & \\
\hline parietal & $4(8)$ & $111(13.1)$ & 0.57 & $0.20-1.62$ & 0.291 & & & \\
\hline occipital & $29(58)$ & $265(31.36)$ & 3.02 & $1.69-5.39$ & $<\mathbf{0 . 0 0 1}$ & & & \\
\hline Bleeding tendency ${ }^{* *}$ & 4 (8.33) & $30(4.65)$ & 1.86 & $0.62-5.52$ & 0.254 & & & \\
\hline Skull fracture ${ }^{* * *}$ & $24(51)$ & $6(1.03)$ & 99.30 & $37.01-266.43$ & $<0.001$ & & & \\
\hline
\end{tabular}

${ }^{*}$ CT abnormality, $\mathrm{n}=50$; no CT abnormality, $\mathrm{n}=845$. $\quad{ }^{* *} \mathrm{CT}$ abnormality, $\mathrm{n}=48$; no CT abnormality, $\mathrm{n}=645$. Bleeding tendency in 34 patients involved antiplatelet agents in 23 , anticoagulants in five, and others in six. ${ }^{* * *} \mathrm{CT}$ abnormality, $\mathrm{n}=47$; no CT abnormality, $\mathrm{n}=577$. CI: confidence interval, GCS: Glasgow Coma Scale, JCS: Japan Coma Scale, LOC: loss of consciousness, MVA: motor vehicle accident.

Table 4 Diagnostic efficiency of proposed indications for computed tomography (CT)

\begin{tabular}{lcc}
\hline & $\begin{array}{c}\text { Intracranial } \\
\text { lesion (+) }\end{array}$ & $\begin{array}{c}\text { Intracranial } \\
\text { lesion (-) }\end{array}$ \\
\hline Indications for CT (+) & 50 & 705 \\
Indications for CT (-) & 0 & 309 \\
\hline \multicolumn{2}{c}{ Sensitivity } & $100 \%$ \\
Specificity & $30.4 \%$ & \\
Positive predictive value & $6.6 \%$ \\
Negative predictive value & $100 \%$ \\
Reduction in CT frequency & $29 \%$ \\
\hline
\end{tabular}

\section{Discussion}

The present study showed that JCS was significantly correlated with GCS in patients with mild head inju- ry. In addition, the intracranial lesion rate was clearly different for patients with JCS score 0 and with JCS score 1. Therefore, JCS is suitable for the evaluation of mild head injury. The CT abnormality rate was $11 \%$ for patients with JCS score 1 , very similar to that observed for patients with GCS score 14 . Because there were no cases in which GCS score 14 was determined to equate to JCS score 0 , and all cases of JCS score 0 were assessed as GCS score 15, only the JCS classification was appropriate for deciding whether to perform CT. The intracranial lesion rate was only $1.6 \%$ in patients with JCS score 0 , and none required surgical treatment.

JCS score 1 is defined as "a state in which the patient does not appear not fully conscious but can correctly answer questions." However, this wording is rather ambiguous and the classification is therefore slightly subjective. ${ }^{22)}$ Nonetheless, patients with JCS score 1 have extremely mild impairment of consciousness. This classification can be influenced 
by various factors such as LOC, amnesia, alcohol and other drugs, psychological shock after traffic accident or assault, and dementia. Therefore, it is difficult to objectively evaluate a state in which consciousness is not completely clear. In this regard, certain mental status tests or orientation and amnesia tests can be useful. Forward reverse digit span and object recall subscore of the mental status test are not correlated with CT abnormality, ${ }^{14)}$ but the Galveston orientation and amnesia tests have a significant relationship with intracranial injury. ${ }^{11)}$

The rate of CT abnormality is $3 \%$ to $13 \%$ and surgical intervention rate is $0.2 \%$ to $0.4 \%$ in patients with GCS score 15 and amnesia/LOC, $3,4,7,14,19,20,27,28)$ and the rate of CT abnormality is $4.9 \%$ to $6.3 \%$ and surgical intervention rate is $0.08 \%$ in patients with GCS score 15 without amnesia/LOC. ${ }^{2,9,25)}$ The present findings were similar, with rate of CT abnormality of $3.5 \%$ and surgical intervention rate of $0.3 \%$.

The indications for CT in patients with GCS score 15 are diffuse headache, ${ }^{5,13,23,24,32,34)}$ nausea, ${ }^{23)}$ vomiting, ${ }^{5,13,23,24,29,32,34)}$ LOC, , $^{5,13,24,32,34)}$ amnesia, ${ }^{5,13,24,29,32,34)}$ seizure, ${ }^{10,32,34)}$ focal neurological signs, ${ }^{5,34)}$ coagulation disorders, ${ }^{5,10,13,23,24,32,34)}$ intoxication with alcohol/drugs, ${ }^{5,24,32,34)}$ previous neurosurgery, ${ }^{5,10,13,24,32)}$ pre-trauma epilepsy, ${ }^{5,24,32)}$ and trauma above the clavicles including clinical signs of skull fracture (skull base or depressed skull fracture). ${ }^{5,10,29,32,34)}$ Mechanisms of injury as indications for CT include pedestrian struck by motor vehicle or occupant ejected from motor vehicle, falling from height $>3$ feet or five stairs, ${ }^{29)}$ involvement in a high-energy accident, and unclear or ambiguous mechanisms. ${ }^{34)}$

Our study also revealed that patients falling from stairs or height and pedestrians in motor vehicle accidents were likely to have intracranial injury. Patients sustaining fall, assault, or crush injury are at risk of intracranial injury compared with patients involved in motor vehicle crashes. ${ }^{4)}$ Moreover, bicyclists and pedestrians struck by cars were more likely to sustain intracranial lesion. ${ }^{2,14)}$ However, the relationship between location of impact and intracranial injury has not previously been evaluated. The present study showed that occipital impact was associated with increased likelihood of intracranial lesion.

Arriving independently decreased the likelihood of intracranial injury, but this finding might have been influenced by the situation in Japan where the ambulance service is easy to use and free of charge. No relationship between bleeding tendency and abnormal CT was found, as bleeding tendency was only examined in 645 of 1,014 patients $(64 \%)$ in the no CT abnormality group. Coagulopathy has been considered a risk factor for intracranial injury, ${ }^{9,33)}$ but low-dose aspirin does not increase the risk of intracranial hemorrhage in patients older than 60 years of age. ${ }^{26)}$ The presence of fracture was only assessed in $59 \%$ of our patients, but had a strong influence on intracranial lesions, as previously reported..$^{5,11,25,31)}$ However, which patients should undergo skull radiography, and timing are unclear. Although the presence of fracture increases the likelihood of intracranial lesion, the sensitivity of skull radiography is not high enough to be a useful screening test, ${ }^{8,12)}$ as confirming the absence of fracture does not rule out intracranial injury. Therefore, CT should be the first choice in patients with suspected intracranial lesion. ${ }^{28)}$ The indication for skull radiography is limited to patients with GCS score 15 and only LOC/amnesia, ${ }^{34)}$ one other symptom, $, 524,32,34)$ or symptoms without vomiting, but only if CT is recommended but not available. ${ }^{25)}$

Many studies have reported increased risk of intracranial lesions in patients with head injury aged over 65 years $^{9,29)}$ or over 60 years. ${ }^{2,4,5,7,16,24,34)}$ Aging is one risk factor, but it is unlikely that there is a specific age threshold above which the risk suddenly increases. ${ }^{24)}$ Analysis of our subjects aged over 65 years old found no significant difference in lesion frequency, but risk does seem to become higher at around 60 years. If age was not considered, two of our present patients with intracranial injury had clear consciousness and no clinical symptom. As both were older than 80 years, it seems that the very elderly should receive special attention with regard to ruling out intracranial injury.

CT is not indicated in patients with head injury without symptoms or risk factors, $5,10,12,17,23,24,32,34)$ for reasons of adverse cost-benefit ratio. ${ }^{5,24)}$ However, the risk of intracranial injury in such low-risk patients is not zero, but appears to be in the region of six in 10,000 patients. ${ }^{17)}$ In contrast, the risk of operable intracranial hematoma in patients with GCS score 15 without other features is estimated at 1 in $31,300 .{ }^{311}$

Cranial trauma, focal neurological deficit, signs of basilar skull fracture, and age over 60 years together had a sensitivity of $91.6 \%$ and a specificity of $46.2 \%$ in patients with head injury in GCS score $>13 .^{2)}$ The Canadian CT Head Rule proposes seven variables indicating that CT should be performed: GCS score $<15$, suspected open or depressed skull fracture, signs of basal skull fracture, vomiting more than twice, age greater than 65 years, amnesia, and dangerous mechanism. ${ }^{29)}$ These indications had $98.4 \%$ sensitivity, $49.6 \%$ specificity, and $46 \%$ CT reduction rate. Eight variables were proposed for patients with GCS scores 14-15, like those in the present study, indicating that CT should be per- 
formed: GCS score 14, signs of skull base fracture, LOC, seizures, neurological deficit, vomiting, headache, and age greater than 65 years. ${ }^{9)}$ These indications had sensitivity of $100 \%$ and specificity of $52.6 \%$. Moreover, four variables were used for patients with GCS score 15 and LOC, indicating that CT should be performed: severe headache, nausea, vomiting, and depressed skull fracture. ${ }^{19)}$ These variables had $65 \%$ sensitivity, $63 \%$ specificity, and $61 \%$ CT reduction rate. Seven variables (headache, vomiting, age over 60 years, drug or alcohol intoxication, short-term memory deficit, trauma above the clavicles, and seizure) had sensitivity of $100 \%$, specificity of $24 \%$, and could decrease CT frequency by $22 \% .^{7}$ These two latter reports suggested that CT is not always necessary just because LOC occurred. Sensitivity for the risk of surgical intervention was $100 \%$ in all reports. These studies are hard to compare, because GCS range and age varied. It is worth noting that too many variables makes a set of indications difficult to use, and determining past history may be uncertain due to LOC or amnesia. Our classification based on seven factors, JCS score 0, headache, nausea, vomiting, LOC, amnesia, and age $\geq 60$ years, is simple and suitable for the emergency clinic and has adequate sensitivity for detecting intracranial lesions. However, other injury may be a risk factor of aggravation in mild head injury, ${ }^{13)}$ so the JCS assessment is applicable only to patients with simple head injury.

Using these criteria, the number of CT scans required can be reduced by $34.5 \%$ (315/912) in patients with GCS score 15 . However, as many as $70 \%$ of patients not deemed to require CT actually underwent scanning because of patient request or social reasons such as medicolegal requirements related to traffic accident or assault. The low cost of CT and insurance factors appeared to influence this finding. The medicolegal aspects are difficult to take into account when adopting criteria for CT use, but the Society of British Neurological Surgeons was advised by a leading medicolegal firm to take the view that such guidelines would be unlikely to expose their authors or the Society endorsing them to any significant risk of legal challenge. ${ }^{1)}$

This study was performed at a single secondary level emergency clinic. Moreover, relatively few cases were evaluated using these proposed indications. Further study is necessary to confirm the validity, but these indications for CT including JCS may be useful in the management of patients with mild head injury. We hope that these results are also helpful for informed consent.

\section{References}

1) Bartlett J, Kett-White R, Mendelow AD, Miller JD, Pickard J, Teasdale G: Recommendations from the Society of British Neurological Surgeons. Br J Neurosurg 12: 349-352, 1998

2) Borczuk P: Predictors of intracranial injury in patients with mild head trauma. Ann Emerg Med 25: 731-736, 1995

3) Culotta VP, Sementilli ME, Gerold K, Watts CC: Clinicopathological heterogeneity in the classification of mild head injury. Neurosurgery 38: 245-250, 1996

4) Dunham CM, Coates S, Cooper C: Compelling evidence for discretionary brain computed tomographic imaging in those patients with mild cognitive impairment after blunt trauma. J Trauma 41: 679-686, 1996

5) Fabbri A, Servadei F, Marchesini G, Morselli-Labate AM, Iervese T, Spada M, Vandelli A: Prospective validation of a proposal for diagnosis and management of patients attending the emergency department for mild head injury. J Neurol Neurosurg Psychiatry 75: 410-416, 2004

6) Gotoh O, Tamura A, Yasui N, Nihei H, Manaka S, Suzuki A, Hadeishi H, Sano K: [Japan Coma Scale in the prediction of outcome after early surgery for aneurysmal subarachnoid hemorrhage]. No To Shinkei 47: 49-55, 1995 (Jpn, with Eng abstract)

7) Haydel MJ, Preston CA, Mills TJ, Luber S, Blaudeau E, DeBlieux PMC: Indications for computed tomography in patients with minor head injury. $\mathrm{N}$ Engl J Med 343: 100-105, 2000

8) Hofman PAM, Nelemans P, Kemerink GJ, Wilmink JT: Value of radiological diagnosis of skull fracture in the management of mild head injury: meta-analysis. J Neurol Neurosurg Psychiatry 68: 416-422, 2000

9) Ibanez J, Arikan F, Pedraza S, Sanchez E, Poca MA, Rodriguez D, Rubio E: Reliability of clinical guidelines in the detection of patients at risk following mild head injury: results of a prospective study. J Neurosurg 100: 825-834, 2004

10) Ingebrigtsen T, Romner B, Kock-Jensen C: Scandinavian guidelines for initial management of minimal, mild, and moderate head injuries. The Scandinavian Neurotrauma Committee. J Trauma 48: 760-766, 2000

11) Iverson GL, Lovell MR, Smith S, Franzen MD: Prevalence of abnormal CT-scans following mild head injury. Brain Inj 14: 1057-1061, 2000

12) Jagoda AS, Cantrill SV, Wears RL, Valadka A, Gallagher EJ, Gottesfeld SH, Pietrzak MP, Bolden J, Bruns JJ Jr, Zimmerman R: Clinical policy: neuroimaging and decisionmaking in adult mild traumatic brain injury in the acute setting. Ann Emerg Med 40: 231-249, 2002

13) The Japan Society of Neurotraumatology: [Guidelines for the treatment/management of severe head injury. The second edition]. Shinkei Gaisho 29 Suppl: 1-115, 
2006 (Jpn)

14) Jeret JS, Mandell M, Anziska B, Lipitz M, Vilceus AP, Ware JA, Zesiewicz TA: Clinical predictors of abnormality disclosed by computed tomography after mild head trauma. Neurosurgery 32: 9-16, 1993

15) Katada K: [CT radiation exposure in Japan: analysis of social factors]. Nippon Hoshasen Gijutsu Gakkai Zasshi 62: 649-656, 2006 (Jpn)

16) Lee ST, Liu TN, Wong CW, Yeh YS, Tzaan WC: Relative risk of deterioration after mild closed head injury. Acta Neurochir (Wien) 135: 136-140, 1995

17) Masters SJ, McClean PM, Arcarese JS, Brown RF, Campbell JA, Freed HA, Hess GH, Hoff JT, Kobrine A, Koziol DF, Marasco JA, Merten DF, Metcalf $\mathrm{H}$, Morrison JL, Rachlin JA, Shaver JW, Thornbury JR: Skull X-ray examinations after head trauma. Recommendations by a multidisciplinary panel and validation study. N Engl J Med 316: 84-91, 1987

18) Menegazzi JJ, Davis EA, Sucov AN, Paris PM: Reliability of the Glasgow Coma Scale when used by emergency physicians and paramedics. J Trauma 34: 46-48, 1993

19) Miller EC, Holmes JF, Derlet RW: Utilizing clinical factors to reduce head CT scan ordering for minor head trauma patients. J Emerg Med 15: 453-457, 1997

20) Nagy KK, Joseph KT, Krosner SM, Roberts RR, Leslie CL, Dufty K, Smith RF, Barrett J: The utility of head computed tomography after minimal head injury. J Trauma 46: 268-270, 1999

21) Norwood SH, McAuley CE, Berne JD, Vallina VL, Creath RG, McLarty J: A prehospital Glasgow Coma Scale score $\leq 14$ accurately predicts the need for full trauma team activation and patient hospitalization after motor vehicle collisions. J Trauma 53: 503-507, 2002

22) Ohta T: [Japan Coma Scale: its correlation with intracranial mass lesions]. Sogo Rinsho 34: 477-482, 1985 (Jpn)

23) Scottish Intercollegiate Guidelines Network: Early Management of Patients With a Head Injury: a National Clinical Guideline. Edinburgh, Scottish Intercollegiate Guidelines Network, 2000, pp 7-18

24) Servadei F, Teasdale G, Merry G; Neurotraumatology Committee of the World Federation of Neurosurgical Societies: Defining acute mild head injury in adults: a proposal based on prognostic factors, diagnosis, and management. J Neurotrauma 18: 657-664, 2001

25) Shiomi N, Echigo T: [A guide to initial management of minor head injury]. No Shinkei Geka 32: 465-470, 2004 (Jpn, with Eng abstract)

26) Spektor S, Agus S, Merkin V, Constantini S: Lowdose aspirin prophylaxis and risk of intracranial hemorrhage in patients older than 60 years of age with mild or moderate head injury: a prospective study. J Neurosurg 99: 661-665, 2003

27) Stein SC, Ross SE: The value of computed tomographic scans in patients with low-risk head injuries. Neurosurgery 26: 638-640, 1990

28) Stein SC, Ross SE: Mild head injury: a plea for rou- tine early CT scanning. J Trauma 33: 11-13, 1992

29) Stiell IG, Wells GA, Vandemheen K, Clement C, Lesiuk H, Laupacis A, McKnight RD, Verbeek R, Brison R, Cass D, Eisenhauer MA, Greenberg GH, Worthington J: The Canadian CT Head Rule for patients with minor head injury. Lancet 357: 1391-1396, 2001

30) Takagi K, Aoki M, Ishii T, Nagashima Y, Narita K, Nakagomi T, Tamura A, Yasui N, Hadeishi H, Taneda M, Sano K: [Japan Coma Scale as a grading scale of subarachnoid hemorrhage: a way to determine the scale]. No Shinkei Geka 26: 509-515, 1998 (Jpn, with Eng abstract)

31) Teasdale GM, Murray G, Anderson E, Mendelow AD, MacMillan R, Jennett B, Brookes M: Risk of acute traumatic intracranial haematoma in children and adults: implications for managing head injuries. Br Med J 300: 363-367, 1990

32) Tomei G, Brambilla GL, Delfini R, Servadei F: Guidelines for minor head injured patients' management in adult age. The Study Group on Head Injury of the Italian Society for Neurosurgery. J Neurosurg Sci 40: 11-15, 1996

33) Volans AP: The risks of minor head injury in the warfarinised patient. J Accid Emerg Med 15: 159-161, 1998

34) Vos PE, Battistin L, Birbamer G, Gerstenbrand F, Potapov A, Prevec T, Stepan Ch A, Traubner P, Twijnstra A, Vecsei L, von Wild K; European Federation of Neurological Societies: EFNS guideline on mild traumatic brain injury: report of an EFNS task force. Eur J Neurol 9: 207-219, 2002

Address reprint requests to: K. Ono, M.D., Division Surgeon, Ground Self Defense Force 7th Division Headquarters, Camp Higashichitose, 1016 Shukubai, Chitose, Hokkaido 066-8577, Japan.

\section{Commentary}

The authors evaluate the use of computed tomography (CT) in 1064 patients with mild head injury seen at an emergency hospital in Tokyo within six hours of injury, and propose screening criteria in this population that would safely reduce the number of CTs done by about 30\%. They employed the Japan Coma Scale (JCS) that has been used in subarachnoid hemorrhage patients, but has not previously been reported in a series of head injury patients, and compared it with the Glasgow Coma Scale (GCS) in these patients. In the series, only 50 patients $(4.7 \%)$ had intracranial pathology and only 7 patients $(<1 \%)$ required surgery because of expanding hematomas.

The screening criteria proposed by Ono et al. are simple - the JCS, age older than 59, loss of consciousness, and presence or absence of headache, nausea, vomiting or amnesia. The authors note that JCS scor- 
ing "is rather ambiguous and ... therefore slightly subjective." The JCS has not yet been validated in larger studies so that whether or not it replaces the GCS remains to be seen. The authors present an excellent discussion of the sensitivity and specificity of their screening method and analyzed other published screening methods as well. All of their cited studies had $100 \%$ sensitivity for detection of intracranial hematomas that required surgery, and some of the studies reported CT reduction rates of $29-61 \%$.

This study and those cited in this manuscript do not report the role of clinical worsening in defining the need for surgery in those who eventually have operation. In this study, "lesion enlargement over several hours" required surgery, but we don't know if some or all of the patients deteriorated clinically as a more important indication of the need for surgery than the screening CT images. The authors note in Figure 2 that "close observation" is valid for many patients with mild head injury. It seems that such close observation might be equally safe in detecting the need for surgery even if fewer admission CTs had been done.

While CTs may be less expensive in Japan than in other parts of the world, there are still costs for equipment purchase and maintenance, and in transport and imaging personnel. CT imaging during this study seemed readily available; some CTs were done "because of patient request or social reasons" even without a medical indication. CT scanning has greatly facilitated the management of patients with head injury and improved their safety, but overutilization in patients with mild head injury in no way benefits patients or health care systems. Perhaps further refinement of indications for CT imaging, including serial neurological examinations, will safely reduce the number of CT scans employed in patients with mild head injury.

Lawrence H. PITTS, M.D. Neurosurgery

University of California San Francisco San Francisco, California, U.S.A.

This is an interesting article trying to determine the indication criteria for CT scanning in patients with mild head injury mainly based on the initial Japan Coma Scale (JCS). There are, however, already many criteria for CT scanning to predict the risk of mild head injury such as the Canadian CT Head Rule or National Institute of Clinical Excellence (NICE) guidelines. Since the medico-legal and social systems are quite different from other Western countries and CT is quite easily available with low expense in Japan, the use of JCS in the prediction of subsequent risk seems to be reasonable. JCS is the common measure to assess the level of consciousness and widely used in the front of the accident and the scene of emergency. Usually GCS 15 corresponds to JCS 0-1 and GCS 14 to JCS 2 according to the definition of these scales. The result of this article shows us suggestions on the significance of the use of JCS. However, the one-digit code of JCS is a subjective and arbitrary measure depending on the responsible persons who manage each patient. Therefore, it is sometimes difficult to differentiate JCS score 1 and 2, and the time of evaluation after injury may also influence the result of assessment. In addition, it is not necessarily possible to obtain accurate information on any episode of amnesia or initial loss of consciousness at the injury from the patients at the time of admission. The preinjury condition of the patients, their ages and the presence of multiple injuries will also influence the assessment of consciousness levels. To confirm the validity of the present study, more rigid inclusion criteria will necessary to draw the final conclusion. Recently, the Emergency Coma Scale (ECS) incorporating the advantages of GCS and JCS has been developed by the Ad Hoc committee organized by several societies of neuroemergency in Japan. The proposal of this new scale may be useful as a more accurate measure of mild consciousness disturbance and may contribute to the establishment of new criteria for CT scanning in mild head injury in the near future.

$$
\begin{array}{r}
\text { Minoru SHIGEMORI, M.D. } \\
\text { Department of Neurosurgery } \\
\text { Kurume University School of Medicine } \\
\text { Kurume, Fukuoka, Japan }
\end{array}
$$

Mild head injury is commonest in the casualty department, accounting for $60 \%$ to $80 \%$ of all head injury. The diagnosis of mild head injury is based on the GCS score. I am not familiar with the Japan Coma Scale (JCS), but this study showed us that JCS was significantly correlated with GCS in patients with mild head injury. CT now is widely used for head injury patients. From this paper, authors propose indications for CT in patients with mild head injury as follows: JCS score $>0$, presence of accessory symptoms and age $>60$ years. The authors used this indication to deal with 168 subsequent patients with GCS score 14-15. The authors think this indication is suitable for clinical situations, since using this criterion, the number of CT scans required can be reduced by $34.5 \%$. I believe that the indications for CT in patients with mild head injury are reasonable and can be widely used in clinical work to deal with mild head injury patients. But there are some other factors influence such as: the patient requests, medicolegal requirements, and doctors' needs.

\section{Reference}

Reilly PL, Bullock R: Head Injury, ed 2. London, Hodder Arnold, 2005, pp 14-69

Shuyuan YANG, M.D. Department of Neurosurgery Tianjin Medical University General Hospital Tianjin, P.R.C. 